\title{
TP53 DNA Binding Domain Mutations Predict Progression-Free Survival of Bevacizumab Therapy in Metastatic Colorectal Cancer
}

\author{
Hung-Chih Hsu ${ }^{1,2}{ }^{\oplus}$, Jeng-Fu You ${ }^{2,3}$, Shu-Jen Chen ${ }^{4}$, Hua-Chien Chen ${ }^{5}$, Chien-Yuh Yeh ${ }^{2,3}$, \\ Wen-Sy Tsai ${ }^{2,3}$ (D), Hsin-Yuan Hung ${ }^{2,3}$, Tsai-Sheng Yang ${ }^{1,2}$, Nina Lapke ${ }^{6, *,+}$ \\ and Kien Thiam Tan $6, *,+(D)$ \\ 1 Division of Hematology-Oncology, Chang Gung Memorial Hospital at Linkou, Taoyuan City 333, Taiwan \\ 2 College of Medicine, Chang Gung University, Taoyuan City 333, Taiwan \\ 3 Division of Colon and Rectal Surgery, Chang Gung Memorial Hospital at Linkou, Taoyuan City 333, Taiwan \\ 4 Chief Scientific Officer, ACT Genomics Co. Ltd., 3F., No.345, Xinhu 2nd Rd., Neihu Dist, \\ Taipei City 114, Taiwan \\ 5 Chief Executive Officer, ACT Genomics Co. Ltd., 3F., No.345, Xinhu 2nd Rd., Neihu Dist, \\ Taipei City 114, Taiwan \\ 6 Department of Medical Informatic, ACT Genomics Co. Ltd., 3F., No.345, Xinhu 2nd Rd., Neihu Dist, \\ Taipei City 114, Taiwan \\ * Correspondence: ninalapke@actgenomics.com (N.L.); jtchen@actgenomics.com (K.T.T.); Tel.: +886-227953660 \\ (ext. 1602) (N.L. \& K.T.T.); Fax: +886-227955016 (N.L. \& K.T.T.) \\ + These authors have contributed equally to this work as senior authors.
}

Received: 8 July 2019; Accepted: 26 July 2019; Published: 30 July 2019

check for updates

\begin{abstract}
Background: Bevacizumab-based regimens are a standard treatment for metastatic colorectal cancer $(\mathrm{mCRC})$ patients, however meaningful clinical biomarkers for treatment benefit remain scarce. (2) Methods: Tumor samples from $36 \mathrm{mCRC}$ patients treated with bevacizumab-based chemotherapy underwent comprehensive genomic profiling. Alterations in frequently altered genes and important signaling pathways were correlated with progression-free survival (PFS). (3) Results: Overall genetic alteration analysis of investigated genes and pathways did not identify promising new predictors of PFS. However, when considering mutation subtypes, TP53 DNA binding domain (DBD) missense mutations were associated with prolonged PFS (HR, 0.41; 95\% CI, 0.13-0.65; $p=0.005$ ). In contrast, TP53 truncating mutations were associated with short PFS (HR, 2.95; 95\% CI, 1.45-27.50; $p=0.017)$. Importantly, neither TP53 mutation subtype was associated with overall response rate. In multivariate analysis, TP53 DBD missense mutations remained an independent PFS predictor (HR, $0.31 ; 95 \%$ CI, 0.13-0.77; $p=0.011)$. The other genetic factor independently associated with PFS were PTPRT/PTPRD deleterious alterations, which we previously identified in a screen for biomarkers of bevacizumab response. (4) Conclusions: TP53 DBD missense mutations may predict prolonged PFS in mCRC patients treated with bevacizumab-based therapy. Analyses of TP53 mutations as clinical biomarkers should take the biological impact of different mutation subtypes into consideration to improve patient stratification.
\end{abstract}

Keywords: metastatic colorectal cancer; bevacizumab therapy; next-generation sequencing; progression-free survival; TP53 DNA binding domain mutation

\section{Introduction}

Colorectal cancer (CRC) represents one of the most prevalent cancer types in both sexes [1]. Although screening is becoming more common, more than $20 \%$ of CRC patients are diagnosed with 
metastatic disease [2]. In addition, $30 \%$ of early stage CRC patients progress to recurrent or metastatic disease [3], and recurrent or metastatic CRC (mCRC) patients have unfavorable outcomes.

Bevacizumab is an antibody binding specifically to the circulating vascular endothelial growth factor A (VEGF-A) [4] and inhibiting tumor angiogenesis. It has been widely used in combination with chemotherapeutic regimens in various cancers, including $\mathrm{MCRC}$, and prolongs $\mathrm{mCRC}$ patient survival in combination with chemotherapeutic agents [5-8]. However, predictive biomarkers for bevacizumab in $\mathrm{mCRC}$ are not yet available as guidance for clinical practice.

Suggested genetic markers for bevacizumab benefit include copy number variations [9]. Mutational markers have also been investigated, but previous studies have mainly focused on the analysis of overall mutations in pre-defined key genes, such as TP53 and KRAS, with limited success $[10,11]$. However, associations could have been missed, since genetic markers of drug benefit could include multiple genes of a certain cancer pathway, since copy number alterations of genes of interest as biomarkers may have been overlooked. On the other hand, mutational subtypes of certain genes may be functionally different and therefore differently impact a cancer treatment outcome, as observed for TP53 mutation subtypes [12].

In a screen for biomarkers of bevacizumab response by comprehensive genomic profiling, we recently identified deleterious mutations and copy loss in the genes PTPRT and PTPRD, phosphatases of the JAK/STAT pathway, as biomarkers of outcome [13]. However, since it has been shown that benefit from bevacizumab can be observed independent of the treatment response [14], we further aimed to identify markers that may be associated with progression-free survival (PFS) in our cohort, but might not have been identified before due to a lack of association with response. For correlation with PFS, we analyzed sequence and copy number variants detected by next-generation sequencing of tumor samples from 36 bevacizumab-treated patients. We analyzed a variety of important cancer signaling pathways, both on a whole pathway and single-gene level. Furthermore, the possibility of a differential association of mutational subtypes in frequently altered genes with PFS was taken into consideration.

\section{Results}

\subsection{Patients}

A total of 36 patients with metastatic colorectal cancer were enrolled, and patients have been characterized in a previous publication from the same study [13]. In brief, all patients were treated with bevacizumab plus chemotherapy with FOLFIRI (irinotecan and infusional 5-fluorouracil with leucovorin) [15]. Patients showed a relatively balanced distribution regarding sex (58\% male, $\mathrm{n}=21$ and $42 \%$ female, $\mathrm{n}=15)$, metastatic pattern ( $53 \%$ synchronous, $\mathrm{n}=19$ and $47 \%$ metachronous, $\mathrm{n}=17$ ) and primary tumor site ( $58 \%$ colon, $n=21$ and $42 \%$ rectum, $n=15)$. The median age was 60 years (range: 33-87 years), and the proportion of patients with more than one metastatic site was 58\% $(n=21)$. The majority of patients harbored low-grade tumors $(92 \%, n=33)$ and received bevacizumab plus chemotherapy as a first-line treatment $(89 \%, \mathrm{n}=32)$. All patients had a microsatellite stable (MSS) disease.

\subsection{Genetic Alterations in Oncogenic Pathways and Progression-Free Survival in Bevacizumab-Treated Patients}

Genetic alteration analysis, including mutations, as well as copy number alterations, was performed for important cancer signaling pathway genes. We then analyzed the relationship between genetic alterations and PFS. An oncoprint plot was created, sorting patients according to their PFS (Figure 1). This sorting approach was feasible in our cohort, since all patients except the two patients with the longest PFS (B00573 and B00527) relapsed during the observation period, preventing the display of censored patients with a short follow-up at inappropriate ranks. 


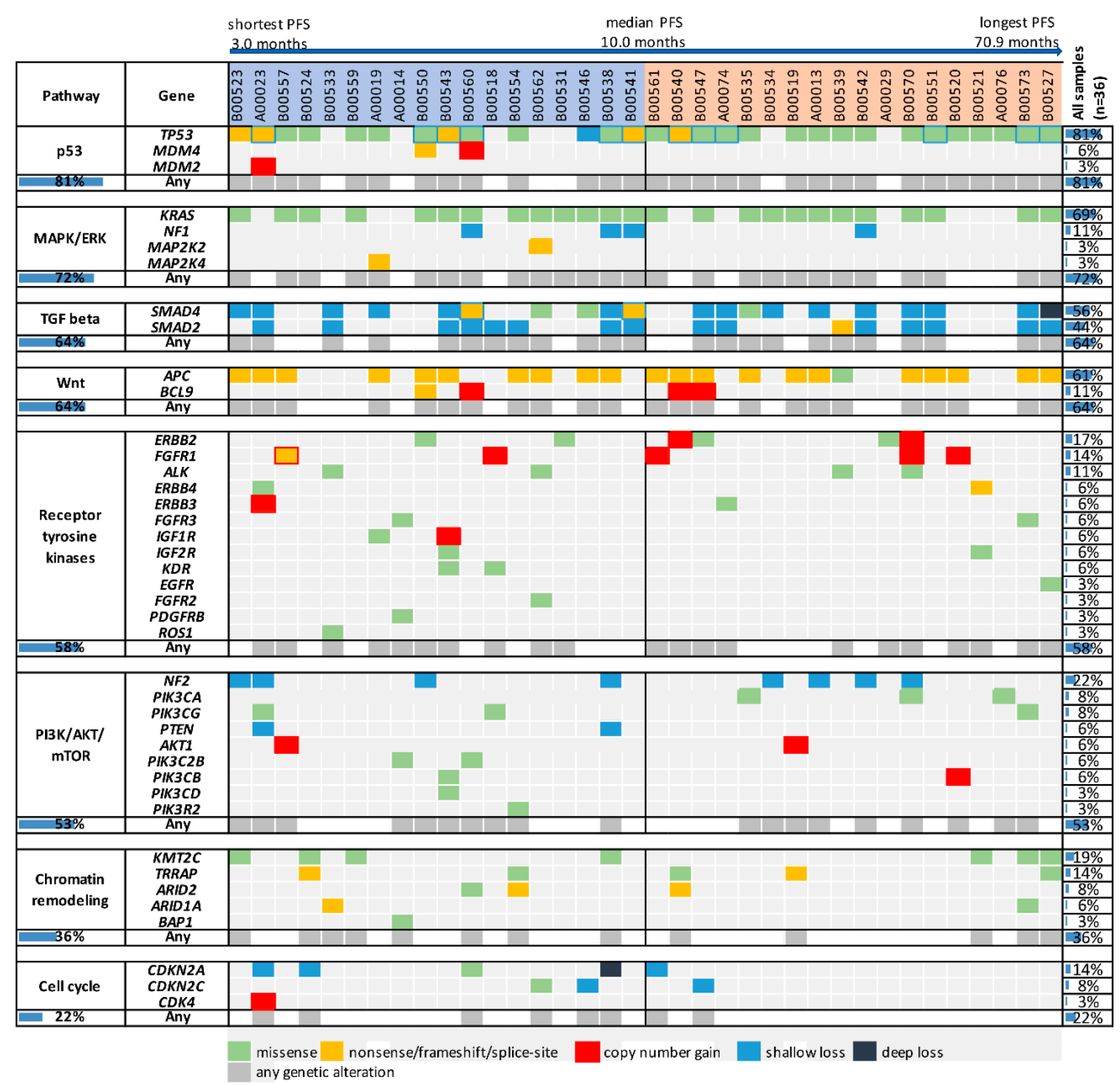

Figure 1. Genetic alterations in oncogenic pathways and frequently mutated genes in bevacizumab-treated patients according to progression-free survival (PFS). Patients were sorted according to their PFS duration, with all patients except the two patients with the longest PFS eventually relapsing during the study period. Genetic alterations are displayed in an oncoprint plot according to their occurrence in genes of important oncogenic pathways. PFS, progression-free survival.

Among the investigated genes, TP53 was the most frequently altered gene $(81 \%, n=29)$. PFS was not different among patients with and without TP53 alterations, although there was a trend towards longer PFS in patients with TP53 alterations (HR, 0.58; 95\% CI, 0.19-1.37; $p=0.188$, Table 1). However, patients with truncating mutations seemed to have a shorter PFS compared to patients with missense mutations (Figure 1). TP53 mutation subtypes may have different biological impacts, since truncating mutations disrupt protein function, whereas missense mutations may be associated with an oncogenic gain-of-function [16]. It is therefore possible that analyzing alterations with discrimination of the mutation subtype may be necessary for this gene. Of note, TP53 deletions were observed both in patients with missense and truncating alterations. 
Table 1. Statistical analysis of the association of progression-free survival (PFS) with frequently altered genes and cancer signaling pathways.

\begin{tabular}{|c|c|c|c|c|c|}
\hline & $\begin{array}{c}\text { Genetic } \\
\text { Alterations }\end{array}$ & n (\%) & $\begin{array}{l}\text { Median PFS } \\
\text { (Months) }\end{array}$ & HR (95\% CI) & $p$ Value \\
\hline All patients & & $36(100)$ & 10.0 & & \\
\hline \multicolumn{6}{|c|}{ Gene } \\
\hline \multirow{2}{*}{ TP53 } & no & $7(19)$ & 9.5 & 1.00 & \multirow{2}{*}{0.188} \\
\hline & yes & $29(81)$ & 11.2 & 0.58 (0.19-1.37) & \\
\hline \multirow{2}{*}{$K R A S$} & no & $11(31)$ & 11.2 & 1.00 & \multirow{2}{*}{0.863} \\
\hline & yes & $25(69)$ & 9.8 & $1.06(0.52-2.17)$ & \\
\hline \multirow{2}{*}{$A P C$} & no & $14(39)$ & 9.7 & 1.00 & \multirow{2}{*}{0.645} \\
\hline & yes & $22(61)$ & 10.7 & $0.85(0.42-1.70)$ & \\
\hline \multirow{2}{*}{ SMAD4 } & no & $16(44)$ & 9.8 & 1.00 & \multirow{2}{*}{0.728} \\
\hline & yes & $20(56)$ & 11.1 & $0.89(0.45-1.74)$ & \\
\hline \multirow{2}{*}{$S M A D 2$} & no & $20(56)$ & 9.9 & 1.00 & \multirow{2}{*}{0.375} \\
\hline & yes & $16(44)$ & 11.1 & $0.74(0.38-1.44)$ & \\
\hline \multirow{2}{*}{$N F 2$} & no & $28(78)$ & 10.0 & 1.00 & \multirow{2}{*}{0.502} \\
\hline & yes & $8(22)$ & 11.9 & $1.30(0.57-3.17)$ & \\
\hline \multirow{2}{*}{ KMT2C } & no & $29(81)$ & 10.1 & 1.00 & \multirow{2}{*}{0.125} \\
\hline & yes & $7(19)$ & 9.8 & $0.51(0.24-1.13)$ & \\
\hline \multirow{2}{*}{$E R B B 2$} & no & $30(83)$ & 9.8 & 1.00 & \multirow{2}{*}{0.915} \\
\hline & yes & $6(17)$ & 11.8 & $1.05(0.43-2.57)$ & \\
\hline \multirow{2}{*}{ FGFR1 } & no & $31(86)$ & 9.8 & 1.00 & \multirow{2}{*}{0.986} \\
\hline & yes & $5(14)$ & 10.1 & $0.99(0.38-2.56)$ & \\
\hline \multirow{2}{*}{ TRRAP } & no & $31(86)$ & 9.8 & 1.00 & \multirow{2}{*}{0.571} \\
\hline & yes & $5(14)$ & 11.2 & $0.74(0.30-1.94)$ & \\
\hline \multirow{2}{*}{$C D K N 2 A$} & no & $31(86)$ & 12.4 & 1.00 & \multirow{2}{*}{0.017} \\
\hline & yes & $5(14)$ & 9.2 & $2.93(1.44-27.10)$ & \\
\hline \multicolumn{6}{|c|}{ Pathway } \\
\hline \multirow{2}{*}{ p53 } & no & $7(19)$ & 9.5 & 1.00 & 0188 \\
\hline & yes & $29(81)$ & 11.2 & $0.58(0.19-1.34)$ & 0.100 \\
\hline MAPK/FRK & no & $10(28)$ & 12.1 & 1.00 & 0640 \\
\hline 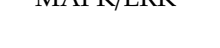 & yes & $26(72)$ & 9.8 & $1.19(0.58-2.43)$ & 0.042 \\
\hline $\mathrm{TCF} \beta$ & no & $13(36)$ & 10.1 & 1.00 & 0947 \\
\hline 100 & yes & $23(64)$ & 9.8 & $0.98(0.49-1.95)$ & 0.947 \\
\hline Wht & no & $13(36)$ & 9.8 & 1.00 & 0815 \\
\hline vilit & yes & $23(64)$ & 10.1 & $0.92(0.46-1.85)$ & 0.010 \\
\hline Receptor tyrosine & no & $15(42)$ & 9.8 & 1.00 & 0594 \\
\hline kinases & yes & $21(58)$ & 10.1 & $0.83(0.42-1.65)$ & דיק \\
\hline PI3K/AKT/mTOR & no & $17(47)$ & 10.1 & 1.00 & 0981 \\
\hline & yes & $19(53)$ & 9.8 & $1.01(0.51-1.98)$ & 0.901 \\
\hline Chromatin & no & $23(64)$ & 12.4 & 1.00 & 0.771 \\
\hline remodeling & yes & $13(36)$ & 9.5 & $0.90(0.44-1.82)$ & \\
\hline Cell cvcle & no & $28(78)$ & 13.1 & 1.00 & 017 \\
\hline & yes & $8(22)$ & 9.6 & $2.44(1.35-11.40)$ & \\
\hline
\end{tabular}

Statistical calculations were performed using the log-rank test. CI, confidence interval; HR, hazard ratio; PFS, progression-free survival.

Among other genes altered in at least five patients (KRAS, APC, SMAD4, SMAD2, NF2, KMT2C, ERBB2, FGFR1, TRRAP and CDKN2A), only CDKN2A alterations were significantly associated with 
PFS. Patients with CDKN2A alterations had shorter PFS than patients without such alterations (HR, 2.93; 95\% CI, 1.44-27.10; $p=0.017$, Table 1). However, CDKN2A is located in chromosomal vicinity to PTPRD, and deleterious alterations in PTPRT and PTPRD are associated with treatment resistance in our cohort [13]. Among the five patients with CDKN2A shallow loss, three patients (A00023, B00524 and B00561) had losses of both PTPRD and CDKN2A, including the two CDKN2A-altered patients with the shortest PFS (A00023, PFS = 3.1 months, and B00524, PFS = 3.3 months). The remaining two patients with CDKN2A alterations (B00538 and B00560) did not have particularly short PFS compared to the median PFS in our cohort (9.2 and 9.7 months, respectively, versus 10.0 months).

Regarding the investigated pathways (p53, MAPK/ERK, TGF $\beta$, Wnt, receptor tyrosine kinases, $\mathrm{PI} 3 \mathrm{~K} / \mathrm{AKT} / \mathrm{mTOR}$, chromatin remodeling, and cell cycle), statistically significant differences in PFS were only observed for the cell cycle (Table 1). However, observed differences were mostly due to $C D K N 2 A$ alterations, and patients without $C D K N 2 A$ alterations, but alterations in other cell cycle genes had PFS durations of 9.5, 9.7 and 12.4 months, respectively. Therefore, no promising new markers of PFS could be identified in our pathway analysis. However, alterations in the JAK/STAT pathway are not included in the graph, since those were previously identified as markers of response, with a simultaneous association with PFS [13].

In summary, the analysis of overall genetic alterations in frequently altered genes or the investigated oncogenic pathways failed to identify new promising biomarkers for PFS. However, for the gene TP53, different biological impacts of mutation subtypes may justify a more refined analysis for this gene. In contrast, an alteration subtype analysis did not seem suitable for other genes. KRAS mutations were activating codon 12 or 13 mutations in 23 of 25 patients, APC harbored truncating mutations in 21 of 22 patients, and SMAD2 and SMAD4 were characterized by inactivating mutations or single copy number losses. Alterations in NF2 and KMT2C were restricted to copy number losses and missense mutations, respectively, and ERBB2, FGFR1, TRRAP and CDKN2A were only altered in five to six patients.

\subsection{TP53 Mutations Detected in the Study Cohort}

In the vast majority of the 29 patients with TP53 alterations, TP53 mutations were detected (97\%, $\mathrm{n}=28$ ). The overall TP53 mutation frequency in our cohort was 78\%, and no patient harbored more than one TP53 mutation. All TP53 mutations for our cohort are listed in Supplementary Table S2, together with mutation classification and associated clinical data. Mutations are displayed according to their amino acid position in Figure 2A, and were categorized into mutation subtypes as described in the Methods. Truncating mutations were detected in $14 \%$ of patients $(n=5)$. The remaining patients with mutations harbored missense mutations, with all of them except for one being located in the DBD $(61 \%, n=22)$. Subtypes of DBD missense mutations were hotspot mutations in $33 \%(n=12)$ of patients, and L2, L3 and LSH missense mutations in 44\% $(\mathrm{n}=16)$ of patients. Both of the latter two mutation categories included the most prominent hotspots of our cohort, $\mathrm{R} 175 \mathrm{H}$ and $\mathrm{R} 273 \mathrm{C} / \mathrm{H}(\mathrm{each} \mathrm{n}=5)$.

TP53 mutations in the TCGA cohort were slightly less common than in our cohort, and 123 mutations were detected in $54 \%(n=121)$ of samples. As in our cohort, missense mutations were the most common mutation subtype $(n=84)$. The majority of those mutations occurred in the DBD, and the most common hotspots were R175H/C ( $n=17)$ and R273H/C ( $n=11)$ (Supplementary Figure S1). 


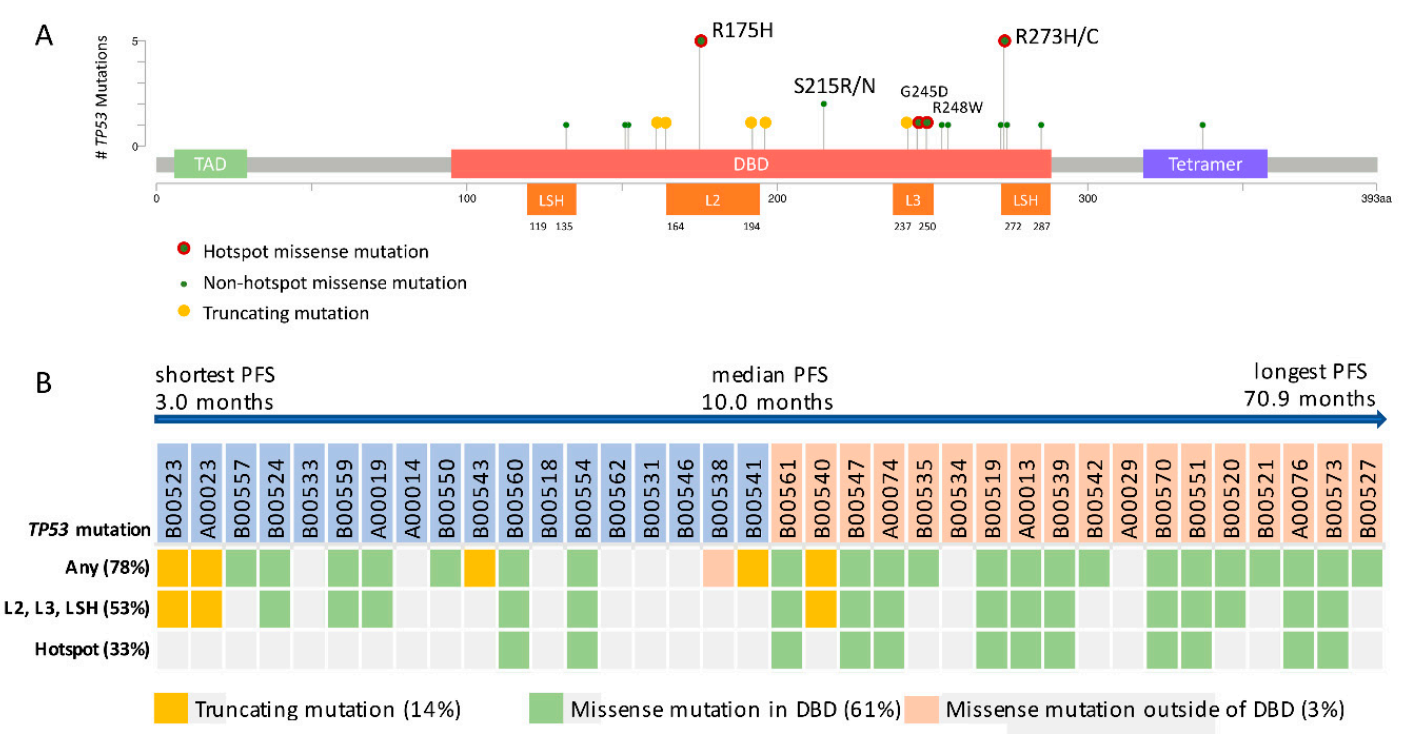

C

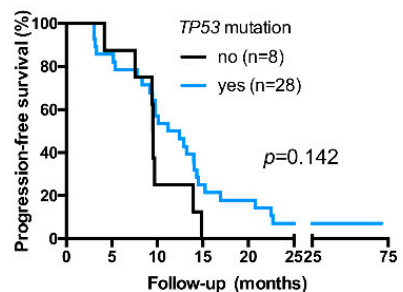

$\mathrm{F}$

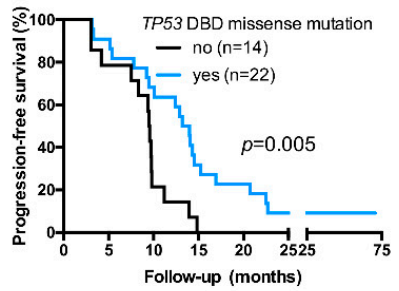

D

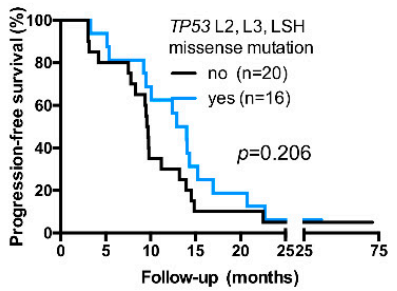

G

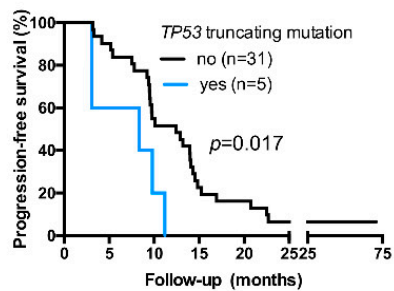

$\mathrm{E}$

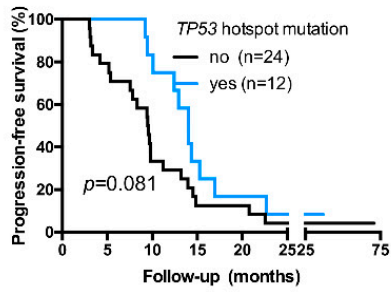

Figure 2. TP53 mutations and PFS. TP53 mutations detected in the present study are depicted according to their protein location (A). Patients were categorized according to their TP53 mutation characteristics and sorted according to their PFS duration, with all patients except the two patients with the longest PFS eventually relapsing during the study period (B). PFS is displayed in Kaplan-Meier plots for patients regarding the occurrence of any TP53 mutations (C), TP53 L2, L3, LSH missense mutations (D), TP53 hotspot mutations (E), TP53 binding domain (DBD) missense mutations (F) and TP53 truncating mutations (G). Statistical analysis was performed by the log-rank test. PFS, progression-free survival.

2.4. TP53 DBD Missense Mutations Are Associated with Prolonged PFS, Whereas Truncating Mutations Are Associated with Short PFS

We next analyzed PFS in patients harboring different TP53 mutation subtypes. The median PFS in the overall cohort was 10.0 months (Table 2, Figure 2B). In patients with any TP53 mutation, L2, L3 and LSH mutations or TP53 hotspot mutations, median PFS was longer (11.8, 13.5 and 14.0 months, respectively), however differences to the rest of the cohort were not statistically significant (Table 2 and Figure 2C-E). In contrast, patients with TP53 DBD missense mutations had prolonged PFS compared to patients without such mutations, the median PFS being 13.6 months versus 9.5 months (HR, 0.41 ; 95\% CI, 0.13-0.65; $p=0.005$; Table 2 and Figure 2F). PFS did not differ in patients with the most common TP53 DBD missense mutations, R175H and R273C/H (Supplementary Figure S2). In spite of 
the low number of patients with TP53 truncating mutations, there was a clear association with short PFS compared to patients without TP53 truncating mutations (HR, 2.95; 95\% CI, 1.45-27.50; $p=0.017$, Table 2 and Figure 2G).

Table 2. TP53 mutation subtypes and clinical outcome.

\begin{tabular}{|c|c|c|c|c|c|c|c|c|}
\hline & n $(\%)$ & $\begin{array}{l}\text { Median PFS } \\
\text { (Months) }\end{array}$ & $\begin{array}{c}\text { HR } \\
(95 \% \mathrm{CI})\end{array}$ & $p$ Value & $\begin{array}{l}\text { Responders } \\
\text { n (\%) }\end{array}$ & $p$ Value & $\begin{array}{l}\text { Median Tumor } \\
\text { Change from } \\
\text { Baseline }\end{array}$ & $p$ Value \\
\hline $\begin{array}{c}\text { All } \\
\text { patients }\end{array}$ & $36(100)$ & 10.0 & & & $18(50)$ & & $-25 \%$ & \\
\hline \multicolumn{9}{|c|}{ TP53 mutation } \\
\hline no & $8(22)$ & 9.5 & 1.00 & \multirow[b]{2}{*}{0.142} & $4(50)$ & \multirow[b]{2}{*}{1.000} & $-25 \%$ & \multirow[b]{2}{*}{0.759} \\
\hline yes & $28(78)$ & 11.8 & $\begin{array}{c}0.57 \\
(0.19-1.24) \\
\end{array}$ & & $14(50)$ & & $-25 \%$ & \\
\hline \multicolumn{9}{|c|}{ TP53 L2, L3, LSH missense mutation } \\
\hline no & $20(56)$ & 9.6 & 1 & \multirow[b]{2}{*}{0.206} & $9(45)$ & \multirow[b]{2}{*}{0.738} & $-17 \%$ & \multirow[b]{2}{*}{0.260} \\
\hline yes & $16(44)$ & 13.5 & $\begin{array}{c}0.65 \\
(0.33-1.27)\end{array}$ & & $9(56)$ & & $-32 \%$ & \\
\hline \multicolumn{9}{|c|}{ TP53 hotspot missense mutation } \\
\hline no & $24(67)$ & 9.5 & 1 & \multirow[b]{2}{*}{0.081} & $10(42)$ & \multirow[b]{2}{*}{0.289} & $-15 \%$ & \multirow[b]{2}{*}{0.029} \\
\hline yes & $12(33)$ & 14.0 & $\begin{array}{c}0.54 \\
(0.28-1.07)\end{array}$ & & $8(67)$ & & $-35 \%$ & \\
\hline \multicolumn{9}{|c|}{ TP53 DBD missense mutation } \\
\hline no & $14(39)$ & 9.5 & 1.00 & \multirow[b]{2}{*}{0.005} & $6(43)$ & \multirow[b]{2}{*}{0.733} & $-17 \%$ & \multirow[b]{2}{*}{0.482} \\
\hline yes & $22(61)$ & 13.6 & $\begin{array}{c}0.41 \\
(0.13-0.65)\end{array}$ & & $12(55)$ & & $-30 \%$ & \\
\hline \multicolumn{9}{|c|}{ TP53 truncating mutation } \\
\hline no & $31(86)$ & 12.4 & 1.00 & \multirow[b]{2}{*}{0.017} & $16(52)$ & \multirow[b]{2}{*}{1.000} & $-30 \%$ & \multirow[b]{2}{*}{0.761} \\
\hline yes & $5(14)$ & 8.3 & $\begin{array}{c}2.95 \\
(1.45-27.50)\end{array}$ & & $2(40)$ & & $-16 \%$ & \\
\hline
\end{tabular}

Statistical calculations were performed using the log-rank test, Fisher's Exact test and Mann-Whitney test, respectively. $\mathrm{CI}$, confidence interval; HR, hazard ratio.

\subsection{TP53 DBD Missense Mutations Are an Independent Predictor of PFS}

Due to their association with PFS, TP53 DBD missense mutations and TP53 truncating mutations were further considered as markers of PFS for bevacizumab-treated patients. TP53 DBD missense mutations were not associated with any other analyzed clinical characteristics, while TP53 truncating mutations were associated with rectal tumors ( $p=0.008$, Supplementary Table S3).

We have previously shown that when considering clinical factors and PTPRT and PTPRD deleterious alterations, rectal tumors and PTPRT and PTPRD deleterious alterations were independent predictors of short PFS. We therefore performed a multivariate analysis considering TP53 DBD missense mutations, TP53 truncating mutations, PTPRT and PTPRD deleterious alterations, and tumor location as PFS predictors. (Table 3). In multivariate analysis, TP53 DBD missense mutations retained statistical significance as an independent PFS predictor (HR, $0.31 ; 95 \% \mathrm{CI}, 0.13-0.77 ; p=0.011$, Table 3 ), together with tumor location and PTPRT/PTPRD deleterious alterations. 
Table 3. Multivariate analysis of Progression-free survival (PFS).

\begin{tabular}{cccc}
\hline Factors & $\mathbf{n}$ & HR (95\% CI) & $p$ Value \\
\hline & Clinical & \\
\hline Primary tumor site (rectum/colon) & $15 / 21$ & $2.36(1.05-5.31)$ & 0.037 \\
\hline & Genetic & & 0.725 \\
\hline TP53 truncating mutations (yes/no) & $5 / 31$ & $1.26(0.35-4.55)$ & 0.011 \\
\hline PP53 DBD missense mutations (yes/no) & $22 / 14$ & $0.31(0.13-0.77)$ & 0.002 \\
\hline $\begin{array}{c}\text { PTPR/PTPRD deleterious alteration } \\
\text { (yes/no) }\end{array}$ & $10 / 26$ & $3.87(1.66-9.00)$ & \\
\hline
\end{tabular}

Multivariate analysis was performed by Cox regression, considering tumor location, TP53 DBD missense mutations, TP53 truncating mutations and PTPRT/PTPRD deleterious alterations as predictive factors for PFS.

\section{Discussion}

Although bevacizumab is a standard first line therapy for metastatic colorectal cancer (5-8), there are still no clinical predictive biomarkers for its use. We previously found an association of deleterious alterations in the genes PTPRT/PTPRD of the JAK/STAT pathway with bevacizumab response status [13]. To extend or analysis beyond response, we correlated the results of comprehensive genomic profiling in our cohort with PFS and found an impact of TP53 mutation subtype on the clinical outcome of bevacizumab therapy in mCRC.

In our study cohort, when considering overall genetic alterations, the only gene significantly correlated with PFS was CDKN2A, with copy number losses predominating. The only pathway correlated with PFS was the cell cycle, an association mostly driven by CDKN2A alterations. However, $C D K N 2 A$ is located near PTPRD on chromosome 9, and its loss was associated with PTPRD loss. Due to this association, $C D K N 2 A$ alterations were not considered as a new independent marker for bevacizumab treatment outcome. Results from the literature do not show survival differences in bevacizumab-treated CRC patients according to KRAS mutation status [10,11,17]. Similarly, TP53 mutation status was not associated with survival in bevacizumab-treated patients [11]. Our results are in line with those studies, although there was a tendency for prolonged PFS for patients with overall TP53 mutations (HR, 0.57; $95 \% \mathrm{CI}, 0.19-1.24 ; p=0.142$ ). When comparing anti-angiogenic regimens to non-anti-angiogenic regimens, patients with TP53 mutations had a higher treatment benefit than TP53 wild-type patients in diverse cancer types [18,19]. Associations were less clear for CRC patients [11,18], however the discrepant results between CRC and other cancers might be partly related to study design and a different prevalence or impact of functionally different TP53 mutation subtypes.

Some CRC studies have found TP53 mutations in about 55\% of patients [20,21]. However, the TP53 mutation rate in non-hypermutated tumors is slightly higher and was about $60 \%$ in the TCGA study [20]. Most importantly, TP53 mutations are enriched in tumors from patients with metastatic disease [22]. In the MSK cohort, TP53 mutation frequencies were 78\% for MSS patients, and ranged between $74 \%$ and $80 \%$ for patients with metastatic disease [22]. In our study, we enrolled patients with metastatic disease, and all patients had MSS tumors. Therefore, the observed TP53 mutation rate of 78\% is within the expected range. Due to the high mutation rate, mutation subtype analysis was feasible, despite our relatively moderate cohort size $(n=36)$. No association with response was found for any TP53 mutation subtypes. However, PFS analysis revealed that TP53 DBD missense mutations conferred a statistically significant and clinically meaningful survival benefit of bevacizumab therapy in mCRC patients (HR, $0.41 ; 95 \% \mathrm{CI}, 0.13-0.65 ; p=0.005)$. In contrast, TP53 truncating mutations were associated with short survival (HR, 2.95; 95\% CI, 1.45-27.50; $p=0.017$ ), although it should be noted that the number of patients with TP53 truncating alterations was extremely small $(n=5)$. In multivariate analysis of PFS, TP53 DBD missense mutations were an independent factor, together with PTPRT/PTPRD deleterious alterations and rectal tumor site. Although positive associations of T53 DBD missense mutations and survival could be prognostic and not predictive, however, the literature does currently not support this 
notion. TP53 missense mutations were associated with lower survival rates in CRC patients, at least in univariate analysis [23]. Similarly, TP53 DBD missense mutations are a negative prognostic factor for survival in breast cancer and oral cavity squamous cell carcinoma [24,25].

Wild type p53 was found to repress the VEGF activity via interaction with several transcription factors, including SP1 and E2F [26,27], and TP53 involvement in angiogenic processes may be considered to explain the observed association with bevacizumab treatment outcome. A recent study showed that TP53 mutation correlated with upregulation of VEGF-A in NSCLC [28]. However, while VEGF-A upregulation has been suggested to be responsible for a better anti-angiogenic treatment outcome in that study, enhanced VEGF-A expression was discussed as a resistance mechanism in CRC [29]. While underlying mechanisms may be complex and are not yet fully understood, it appears reasonable that different TP53 mutation subtypes may have different impacts on angiogenesis and bevacizumab treatment outcome.

TP53 mutations may have different functional consequences [30]: loss of function [31], selection of function [20] and gain of function [32]. A gain of function means a gain of oncogenic function such as promoting cell proliferation, anti-apoptosis, migration, invasion, angiogenesis, and metastasis [33-35]. While truncating TP53 mutations likely result in a loss of wild-type protein function, many TP53 DBD missense mutations may lead to the acquisition of new functions, e.g., by $\mathrm{p} 53$ binding to transcription factors and modulation of target gene expression [20,36], and certain TP53 DBD missense mutations have been suggested to promote angiogenesis [37]. In this context, it would be interesting to perform gene expression profiling to analyze whether the presence of TP53 DBD missense mutations is related to changes in gene expression that could explain an association with bevacizumab treatment outcome. Such experiments could further be designed to evaluate a possible impact of altered interactions between mutant p53 and other transcription factors.

Using TP53 DBD missense mutations for patient stratification appears promising considering the relatively high difference in PFS between marker-positive and negative patients (HR, 0.41) [38]. However, due to the small sample size in our study, it is essential to validate our results in larger patient cohorts. Another limitation of our study is its retrospective nature, and the findings should be confirmed in prospective studies.

\section{Methods}

\subsection{Patients, Treatment and Next-Generation Sequencing}

Study approval and written informed consent were provided by the Institutional Review Board at the Chang Gung Memorial Hospital (IRB 102-2850A3) and all included patients, respectively. Patient enrollment criteria, details regarding the next-generation sequencing of tumor samples, and sequence and copy number variant identification have described in a previous study of the same patient cohort [13].

\subsection{Variant Classification}

Shallow copy number losses were defined as an observed copy number $<2$ with SNP analysis indicating a loss of heterozygosity $(\mathrm{LOH})$ in the gene of interest. Analyzed SNPs included those present in the gene of interest or within the chromosomal vicinity within or beyond the cytoband harboring the gene of interest. If the gene of interest had no suitable SNPs, SNPs on both sides of the gene needed to indicate an LOH. Deep losses were defined as observed copy numbers $\leq 1$ without apparent LOH. Copy number gains were defined as observed copy numbers $\geq 3$ with copy numbers in the tumor being $\geq 3.5$.

Copy number variants could be included the in functional analysis if they were copy number losses of genes inactivating investigated oncogenic pathways or gains of genes activating those pathways. Investigated genes for which copy numbers $<2$ or gains were observed in our study patients, as well their inclusion in copy number analysis, are listed in Supplementary Table S1. 
TP53 mutations were classified as (1) any TP53 mutations, (2) TP53 truncating mutations, namely frameshift, nonsense and splice site variants, (3) TP53 DNA binding domain (DBD) missense mutations, namely missense variants at amino acids 95-289, (4) TP53 hotspot missense variants, namely at positions R175, Y220, G245, R248, R273, R282 [39,40], and (5) variants in L2, L3 and LSH, namely mutations occurring at the L2 amino acid positions 164-194, the L3 positions 237-250 or the LSH positions 119-135/272-287. The graphical visualization of results was based on tools provided by cBioPortal $[41,42]$.

\subsection{Statistical Analysis}

The statistical evaluation of study results was performed with GraphPad Prism, v. 6.0 and SPSS, v. 20.0.0. Used statistical tests were the Fisher's Exact tests for categorial outcomes, the Mann-Whitney test for tumor change from baseline and the log-rank test and Cox regression for survival outcomes. For multivariate analysis, Cox regression was performed using the "Enter" method (SPSS).

\section{Conclusions}

The present study demonstrated the clinical utility of targeted next-generation sequencing in mCRC patients to identify genetic biomarkers for anti-angiogenic therapy. To our knowledge, this is the first study to suggest TP53 DBD missense mutations as a biomarker of sensitivity to bevacizumab treatment in $\mathrm{mCRC}$. However, its predictive value warrants further confirmation in clinical studies.

Supplementary Materials: The following are available online at http://www.mdpi.com/2072-6694/11/8/1079/s1. Table S1: Gene selection for copy number analysis. Genes analyzed in this study for which patients had copy number gains are listed, and genes for which these gains were included in the genetic alterations correlated with PFS are indicated. Additionally, genes for which patients had observed copy numbers $<2$ are listed. Genes for which copy number loss was further considered for analysis of shallow loss/deep loss and correlation with PFS are indicated. PFS, progression-free survival; Table S2: TP53 mutations and clinical outcome for all study patients. Data of clinical outcome and results of TP53 mutation analysis, including mutation categories for detected TP53 mutations, are listed for all study patients. PFS, progression-free survival; Table S3: Clinicopathological characteristics of patients with TP53 DBD missense and TP53 truncating mutations. Patient characteristics were analyzed for patients with TP53 DBD missense mutations versus patients with wild-type TP53 or TP53 non-DBD missense mutations. Additionally, patient characteristics were compared for patients with TP53 truncating mutations versus patients with wild-type TP53 or TP53 non-truncating mutations. Statistical calculations were performed using the Fisher's Exact test; Figure S1: TP53 mutations in the TCGA study. A graph displaying all TP53 mutations detected in the TCGA colorectal cancer patient cohort $(n=224)$ according to their amino acid position is shown; Figure S2: PFS in patients with TP53 R175H and R273H/C mutations. PFS was analyzed for patients with TP53 R175H and $\mathrm{R} 273 \mathrm{H} / \mathrm{C}$ mutations (each $\mathrm{n}=5$ ). Statistical calculations were performed using the log-rank test. PFS, progression-free survival.

Author Contributions: Conceptualization, H.-C.H., J.-F.Y., N.L. and K.T.T. Data curation; H.-C.H., J.-F.Y., S.-J.C., H.-C.C., C.-Y.Y., W.-S.T., H.-Y.H., T.-S.Y., N.L. and K.T.T.; Formal analysis, H.-C.H., S.-J.C., H.-C.C., N.L. and K.T.T.; Funding acquisition, H.-C.H. and J.-F.Y.; Investigation, H.-C.H., J.-F.Y., C.-Y.Y., W.-S.T., H.-Y.H., T.-S.Y., N.L. and K.T.T.; Methodology, H.-C.H., S.-J.C., H.-C.C., N.L. and K.T.T.; Project administration, H.-C.H., N.L. and K.T.T.; Resources, H.-C.H., J.-F.Y., S.-J.C., H.-C.C., C.-Y.Y., W.-S.T., H.-Y.H., T.-S.Y., N.L. and K.T.T.; Software, S.-J.C., H.-C.C., N.L. and K.T.T.; Supervision, H.-C.H., N.L. and K.T.T.; Validation, H.-C.H., N.L. and K.T.T.; Visualization, H.-C.H., N.L. and K.T.T.; Writing—original draft, H.-C.H.; Writing—review \& editing, N.L. and K.T.T., N.L. and T.K.T. contributed equally as corresponding authors.

Funding: This work was supported by ACT Genomics, Co. Ltd., and by grants from the Chang Gung Memorial Hospital, Taiwan (CORPG3F0063) and (CMRPG3C1841) to J.F. You and H.C. Hsu.

Acknowledgments: While this study aims to identify markers associated with PFS of bevacizumab-treated patients, results from this patient cohort regarding markers of treatment response have previously been published (13). There is a partial overlap of results presented in this study with a poster presentation at the ESMO Asia 2018 congress (Annals of Oncology (2018) 29 (suppl_9): ix113-ix120. 10.1093/annonc/mdy441).

Conflicts of Interest: Kien Thiam Tan, Nina Lapke, Shu-Jen Chen, and Hua-Chien Chen are employees of ACT Genomics, Co. Ltd. 


\section{References}

1. International Agency for Research on Cancer WHO. GLOBOCAN 2012: Estimated Cancer Incidence, Mortality and Prevalence Worldwide in 2012. World Fact Sheet. 2012 (Last Update 2012). Available online: http://globocan.iarc.fr/Pages/fact_sheets_population.aspx (accessed on 8 September 2016).

2. National Cancer Institute. SEER Cancer Statistics Factsheets: Colon and Rectum Cancer. 2016 (Last Update 2016). Available online: http://seer.cancer.gov/statfacts/html/colorect.html (accessed on 23 August 2016).

3. Bockelman, C.; Engelmann, B.E.; Kaprio, T.; Hansen, T.F.; Glimelius, B. Risk of recurrence in patients with colon cancer stage II and III: A systematic review and meta-analysis of recent literature. Acta Oncol. 2015, 54, 5-16. [CrossRef] [PubMed]

4. Ferrara, N. Molecular and biological properties of vascular endothelial growth factor. J. Mol. Med. 1999, 77, 527-543. [CrossRef] [PubMed]

5. Hurwitz, H.; Fehrenbacher, L.; Novotny, W.; Cartwright, T.; Hainsworth, J.; Heim, W.; Berlin, J.; Baron, A.; Griffing, S.; Holmgren, E.; et al. Bevacizumab plus irinotecan, fluorouracil, and leucovorin for metastatic colorectal cancer. N. Engl. J. Med. 2004, 350, 2335-2342. [CrossRef] [PubMed]

6. Tebbutt, N.C.; Wilson, K.; Gebski, V.J.; Cummins, M.M.; Zannino, D.; Van Hazel, G.A.; Robinson, B.; Broad, A.; Ganju, V.; Ackland, S.P.; et al. Capecitabine, bevacizumab, and mitomycin in first-line treatment of metastatic colorectal cancer: Results of the Australasian Gastrointestinal Trials Group Randomized Phase III MAX Study. J. Clin. Oncol. Off. J. Am. Soc. Clin. Oncol. 2010, 28, 3191-3198. [CrossRef]

7. Kabbinavar, F.; Irl, C.; Zurlo, A.; Hurwitz, H. Bevacizumab improves the overall and progression-free survival of patients with metastatic colorectal cancer treated with 5-fluorouracil-based regimens irrespective of baseline risk. Oncology 2008, 75, 215-223. [CrossRef]

8. Cunningham, D.; Lang, I.; Marcuello, E.; Lorusso, V.; Ocvirk, J.; Shin, D.B.; Jonker, D.; Osborne, S.; Andre, N.; Waterkamp, D.; et al. Bevacizumab plus capecitabine versus capecitabine alone in elderly patients with previously untreated metastatic colorectal cancer (AVEX): An open-label, randomised phase 3 trial. Lancet Oncol. 2013, 14, 1077-1085. [CrossRef]

9. Smeets, D.; Miller, I.S.; O'Connor, D.P.; Das, S.; Moran, B.; Boeckx, B.; Gaiser, T.; Betge, J.; Barat, A.; Klinger, R.; et al. Copy number load predicts outcome of metastatic colorectal cancer patients receiving bevacizumab combination therapy. Nat. Commun. 2018, 9, 4112. [CrossRef]

10. Hurwitz, H.I.; Yi, J.; Ince, W.; Novotny, W.F.; Rosen, O. The clinical benefit of bevacizumab in metastatic colorectal cancer is independent of K-ras mutation status: Analysis of a phase III study of bevacizumab with chemotherapy in previously untreated metastatic colorectal cancer. Oncologist 2009, 14, 22-28. [CrossRef]

11. Ince, W.L.; Jubb, A.M.; Holden, S.N.; Holmgren, E.B.; Tobin, P.; Sridhar, M.; Hurwitz, H.I.; Kabbinavar, F.; Novotny, W.F.; Hillan, K.J.; et al. Association of k-ras, b-raf, and p53 status with the treatment effect of bevacizumab. J. Natl. Cancer Inst. 2005, 97, 981-989. [CrossRef]

12. Brachova, P.; Mueting, S.R.; Carlson, M.J.; Goodheart, M.J.; Button, A.M.; Mott, S.L.; Dai, D.; Thiel, K.W.; Devor, E.J.; Leslie, K.K. TP53 oncomorphic mutations predict resistance to platinum and taxanebased standard chemotherapy in patients diagnosed with advanced serous ovarian carcinoma. Int. J. Oncol. 2015, 46, 607-618. [CrossRef]

13. Hsu, H.C.; Lapke, N.; Chen, S.J.; Lu, Y.-J.; Jhou, R.-S.; Yeh, C.-Y.; Tsai, W.-S.; Hung, H.-Y.; Hsieh, J.C.-H.; Yang, T.-S.; et al. PTPRT and PTPRD Deleterious Mutations and Deletion Predict Bevacizumab Resistance in Metastatic Colorectal Cancer Patients. Cancers 2018, 10, 314. [CrossRef] [PubMed]

14. Grothey, A.; Hedrick, E.E.; Mass, R.D.; Sarkar, S.; Suzuki, S.; Ramanathan, R.K.; Hurwitz, H.I.; Goldberg, R.M.; Sargent, D.J. Response-independent survival benefit in metastatic colorectal cancer: A comparative analysis of N9741 and AVF2107. J. Clin. Oncol. Off. J. Am. Soc. Clin. Oncol. 2008, 26, 183-189. [CrossRef] [PubMed]

15. Fuchs, C.S.; Marshall, J.; Mitchell, E.; Wierzbicki, R.; Ganju, V.; Jeffery, M.; Schulz, J.; Richards, D.; Soufi-Mahjoubi, R.; Wang, B.; et al. Randomized, controlled trial of irinotecan plus infusional, bolus, or oral fluoropyrimidines in first-line treatment of metastatic colorectal cancer: Results from the BICC-C Study. J. Clin. Oncol. Off. J. Am. Soc. Clin. Oncol. 2007, 25, 4779-4786. [CrossRef] [PubMed]

16. Muller, P.A.; Vousden, K.H. Mutant p53 in cancer: New functions and therapeutic opportunities. Cancer Cell 2014, 25, 304-317. [CrossRef] [PubMed] 
17. Sun, D.C.; Shi, Y.; Wang, Y.R.; Lv, Y.; Yan, H.; Mao, H.; Wang, Z.-K.; Wu, Z.-Y.; Shi, W.-W.; Dai, G.-H. KRAS mutation and primary tumor location do not affect efficacy of bevacizumab-containing chemotherapy in stagae IV colorectal cancer patients. Sci. Rep. 2017, 7, 14368. [CrossRef] [PubMed]

18. Said, R.; Hong, D.S.; Warneke, C.L.; Lee, J.J.; Wheler, J.J.; Janku, F.; Naing, A.; Falchook, G.S.; Fu, S.; Piha-Paul, S.; et al. P53 mutations in advanced cancers: Clinical characteristics, outcomes, and correlation between progression-free survival and bevacizumab-containing therapy. Oncotarget 2013, 4, 705-714. [CrossRef]

19. Wheler, J.J.; Janku, F.; Naing, A.; Li, Y.; Stephen, B.; Zinner, R.; Subbiah, V.; Fu, S.; Karp, D.; Falchook, G.S.; et al. TP53 Alterations Correlate with Response to VEGF/VEGFR Inhibitors: Implications for Targeted Therapeutics. Mol. Cancer Ther. 2016, 15, 2475-2485. [CrossRef] [PubMed]

20. Cancer Genome Atlas, N. Comprehensive molecular characterization of human colon and rectal cancer. Nature 2012, 487, 330-337. [CrossRef]

21. Lopez, I.; Oliveira, L.P.; Tucci, P.; Alvarez-Valin, F.; Coudry, R.A.; Marin, M. Different mutation profiles associated to P53 accumulation in colorectal cancer. Gene 2012, 499, 81-87. [CrossRef]

22. Yaeger, R.; Chatila, W.K.; Lipsyc, M.D.; Hechtman, J.F.; Cercek, A.; Sanchez-Vega, F.; Jayakumaran, G.; Middha, S.; Zehir, A.; Donoghue, M.T.A.; et al. Clinical Sequencing Defines the Genomic Landscape of Metastatic Colorectal Cancer. Cancer Cell 2018, 33, 125-136e3. [CrossRef]

23. Samowitz, W.S.; Curtin, K.; Ma, K.N.; Edwards, S.; Schaffer, D.; Leppert, M.F.; Slattery, M.L. Prognostic significance of p53 mutations in colon cancer at the population level. Int. J. Cancer 2002, 99, 597-602. [CrossRef] [PubMed]

24. Vegran, F.; Rebucci, M.; Chevrier, S.; Cadouot, M.; Boidot, R.; Lizard-Nacol, S. Only missense mutations affecting the DNA binding domain of p53 influence outcomes in patients with breast carcinoma. PLOS ONE 2013, 8, e55103. [CrossRef] [PubMed]

25. Lapke, N.; Lu, Y.J.; Liao, C.T.; Lee, L.-Y.; Lin, C.-Y.; Wang, H.-M.; Ng, S.-H.; Chen, S.-J.; Yen, T.-C. Missense mutations in the TP53 DNA-binding domain predict outcomes in patients with advanced oral cavity squamous cell carcinoma. Oncotarget 2016, 7, 44194-44210. [CrossRef] [PubMed]

26. Qin, G.; Kishore, R.; Dolan, C.M.; Silver, M.; Wecker, A.; Luedemann, C.N.; Thorne, T.; Hanley, A.; Curry, C.; Heyd, L.; et al. Cell cycle regulator E2F1 modulates angiogenesis via p53-dependent transcriptional control of VEGF. Proc. Natl. Acad. Sci. USA 2006, 103, 11015-11020. [CrossRef] [PubMed]

27. Pal, S.; Datta, K.; Mukhopadhyay, D. Central role of p53 on regulation of vascular permeability factor/vascular endothelial growth factor (VPF/VEGF) expression in mammary carcinoma. Cancer Res. 2001, 61, $6952-6957$. [PubMed]

28. Schwaederle, M.; Lazar, V.; Validire, P.; Hansson, J.; Lacroix, L.; Soria, J.-C.; Pawitan, Y.; Kurzrock, R. VEGF-A Expression Correlates with TP53 Mutations in Non-Small Cell Lung Cancer: Implications for Antiangiogenesis Therapy. Cancer Res. 2015, 75, 1187-1190. [CrossRef] [PubMed]

29. Wang, S.; Xiao, Z.; Hong, Z.; Jiao, H.; Zhu, S.; Zhao, Y.; Bi, J.; Qiu, J.; Zhang, D.; Yan, J.; et al. FOXF1 promotes angiogenesis and accelerates bevacizumab resistance in colorectal cancer by transcriptionally activating VEGFA. Cancer Lett. 2018, 439, 78-90. [CrossRef]

30. Kastenhuber, E.R.; Lowe, S.W. Putting p53 in Context. Cell 2017, 170, 1062-1078. [CrossRef]

31. Freed-Pastor, W.A.; Prives, C. Mutant p53: One name, many proteins. Genes Dev 2012, 26, 1268-1286. [CrossRef]

32. Aschauer, L.; Muller, P.A. Novel targets and interaction partners of mutant p53 Gain-Of-Function. Biochem. Soc. Trans. 2016, 44, 460-466. [CrossRef]

33. Liu, J.; Zhang, C.; Feng, Z. Tumor suppressor p53 and its gain-of-function mutants in cancer. Acta Biochim. Biophys. Sin. (Shanghai) 2014, 46, 170-179. [CrossRef] [PubMed]

34. Muller, P.A.; Vousden, K.H. p53 mutations in cancer. Nat. Cell Biol. 2013, 15, 2-8. [CrossRef] [PubMed]

35. Brosh, R.; Rotter, V. When mutants gain new powers: News from the mutant p53 field. Nat. Rev. Cancer 2009, 9, 701-713. [CrossRef] [PubMed]

36. Kim, M.P.; Lozano, G. Mutant p53 partners in crime. Cell Death Differ. 2018, 25, 161-168. [CrossRef] [PubMed]

37. Fontemaggi, G.; Dell'Orso, S.; Trisciuoglio, D.; Shay, T.; Melucci, E.; Fazi, F.; Terrenato, I.; Mottolese, M.; Muti, P.; Domany, E.; et al. The execution of the transcriptional axis mutant p53, E2F1 and ID4 promotes tumor neo-angiogenesis. Nat. Struct. Mol. Biol. 2009, 16, 1086-1093. [CrossRef] [PubMed] 
38. Gonzalez-Vacarezza, N.; Alonso, I.; Arroyo, G.; Martínez, J.; De Andrés, F.; Llerena, A.; Estévez-Carrizo, F. Predictive biomarkers candidates for patients with metastatic colorectal cancer treated with bevacizumab-containing regimen. Drug Metab. Personal. Ther. 2016, 31, 83-90. [CrossRef] [PubMed]

39. Warren, R.S.; Atreya, C.E.; Niedzwiecki, D.; Weinberg, V.K.; Donner, D.B.; Mayer, R.J.; Goldberg, R.M.; Compton, C.C.; Zuraek, M.B.; Ye, C.; et al. Association of TP53 mutational status and gender with survival after adjuvant treatment for stage III colon cancer: Results of CALGB 89803. Clin. Cancer Res. 2013, 19, 5777-5787. [CrossRef]

40. Xu, J.; Wang, J.; Hu, Y.; Qian, J.; Xu, B.; Chen, H.; Zou, W.; Fang, J.-Y. Unequal prognostic potentials of p53 gain-of-function mutations in human cancers associate with drug-metabolizing activity. Cell Death Dis. 2014, 5, e1108. [CrossRef]

41. Gao, J.; Aksoy, B.A.; Dogrusoz, U.; Dresdner, G.; Gross, B.; Sumer, S.O.; Sun, Y.; Jacobsen, A.; Sinha, R.; Larsson, E.; et al. Integrative analysis of complex cancer genomics and clinical profiles using the cBioPortal. Sci. Signal. 2013, 6, pl1. [CrossRef]

42. Cerami, E.; Gao, J.; Dogrusoz, U.; Gross, B.E.; Sumer, S.O.; Aksoy, B.A.; Jacobsen, A.; Byrne, C.J.; Heuer, M.L.; Larsson, E.; et al. The cBio cancer genomics portal: An open platform for exploring multidimensional cancer genomics data. Cancer Discov. 2012, 2, 401-404. [CrossRef]

(C) 2019 by the authors. Licensee MDPI, Basel, Switzerland. This article is an open access article distributed under the terms and conditions of the Creative Commons Attribution (CC BY) license (http://creativecommons.org/licenses/by/4.0/). 